\title{
ORIGINAL
}

\section{Targeting two different levels of both arterial carbon dioxide and arterial oxygen after cardiac arrest and resuscitation: a randomised pilot trial}

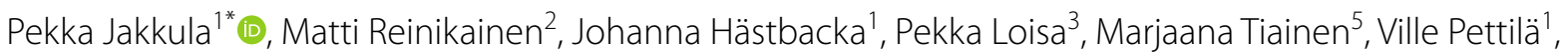
Jussi Toppila ${ }^{6}$, Marika Lähde ${ }^{4}$, Minna Bäcklund ${ }^{1}$, Marjatta Okkonen' ${ }^{1}$, Stepani Bendel ${ }^{7}$, Thomas Birkelund ${ }^{8}$, Anni Pulkkinen" ${ }^{9}$, Jonna Heinonen ${ }^{1}$, Tuukka Tikka ${ }^{1}$, Markus B. Skrifvars ${ }^{1,10}$ and COMACARE study group

(C) 2018 The Author(s)

\begin{abstract}
Purpose: We assessed the effects of targeting low-normal or high-normal arterial carbon dioxide tension $\left(\mathrm{PaCO}_{2}\right)$ and normoxia or moderate hyperoxia after out-of-hospital cardiac arrest (OHCA) on markers of cerebral and cardiac injury.

Methods: Using a $2^{3}$ factorial design, we randomly assigned 123 patients resuscitated from OHCA to low-normal (4.5-4.7 kPa) or high-normal (5.8-6.0 kPa) $\mathrm{PaCO}_{2}$ and to normoxia (arterial oxygen tension $\left[\mathrm{PaO}_{2}\right] 10-15 \mathrm{kPa}$ ) or moderate hyperoxia $\left(\mathrm{PaO}_{2} 20-25 \mathrm{kPa}\right)$ and to low-normal or high-normal mean arterial pressure during the first $36 \mathrm{~h}$ in the intensive care unit. Here we report the results of the low-normal vs. high-normal $\mathrm{PaCO}_{2}$ and normoxia vs. moderate hyperoxia comparisons. The primary endpoint was the serum concentration of neuron-specific enolase (NSE) $48 \mathrm{~h}$ after cardiac arrest. Secondary endpoints included S100B protein and cardiac troponin concentrations, continuous electroencephalography (EEG) and near-infrared spectroscopy (NIRS) results and neurologic outcome at 6 months.

Results: In total 120 patients were included in the analyses. There was a clear separation in $\mathrm{PaCO}_{2}(p<0.001)$ and $\mathrm{PaO}_{2}(p<0.001)$ between the groups. The median (interquartile range) NSE concentration at $48 \mathrm{~h}$ was $18.8 \mu \mathrm{g} / \mathrm{l}(13.9-$ $28.3 \mu \mathrm{g} / \mathrm{l})$ in the low-normal $\mathrm{PaCO}_{2}$ group and $22.5 \mu \mathrm{g} / \mathrm{l}(14.2-34.9 \mu \mathrm{g} / \mathrm{l})$ in the high-normal $\mathrm{PaCO}_{2}$ group, $p=0.400$; and $22.3 \mu \mathrm{g} / \mathrm{l}(14.8-27.8 \mu \mathrm{g} / \mathrm{l})$ in the normoxia group and $20.6 \mu \mathrm{g} / \mathrm{l}(14.2-34.9 \mu \mathrm{g} / \mathrm{l})$ in the moderate hyperoxia group, $p=0.594)$. High-normal $\mathrm{PaCO}_{2}$ and moderate hyperoxia increased NIRS values. There were no differences in other secondary outcomes.
\end{abstract}

Conclusions: Both high-normal $\mathrm{PaCO}_{2}$ and moderate hyperoxia increased NIRS values, but the NSE concentration was unaffected.

\footnotetext{
*Correspondence: pekka.jakkula@hus.fi

${ }^{1}$ Department of Anaesthesiology, Intensive Care and Pain Medicine,

University of Helsinki and Helsinki University Hospital, Helsinki, Finland

Full author information is available at the end of the article
}

\section{实


Registration: ClinicalTrials.gov, NCT02698917. Registered on January 26, 2016.

Keywords: Carbon dioxide, Oxygen, Cardiac arrest, Intensive care, Neuron-specific enolase (NSE), Hypoxic ischemic encephalopathy, Mechanical ventilation

\section{Introduction}

Hypoxic ischaemic encephalopathy (HIE) is the most common cause of disability and death after out-ofhospital cardiac arrest (OHCA) [1,2]. The developing neurological damage is initially related to an ischaemiareperfusion injury and reactive oxygen species (ROS), which may increase the oxidative damage to the brain [3]. This is followed by cerebral hypoperfusion, possibly caused by increased vasoconstriction during the first $72 \mathrm{~h}$ of post-resuscitation care, further aggravating the developing HIE [4]. Previous studies have suggested a decrease in cerebral blood flow and an increase in oxygen extraction in cardiac arrest patients [5].

Arterial carbon dioxide tension $\left(\mathrm{PaCO}_{2}\right)$ is a major determinant of cerebral blood flow (CBF) [6]. In experimental studies, carbon dioxide seems to have anticonvulsive [7], anti-inflammatory and antioxidant properties [8], suggesting a protective role of $\mathrm{PaCO}_{2}$ in the development of HIE. According to a recent meta-analysis of observational data, both hypocapnia and hypercapnia are associated with poor outcomes after cardiac arrest [9]. One randomised controlled trial with 83 patients found, on the contrary, that targeting mild hypercapnia (6.7$7.3 \mathrm{kPa})$ after cardiac arrest attenuated the increase of neuron-specific enolase (NSE) concentrations over time, suggesting a possible protective effect of mild hypercapnia against neurological injury [10]. Concerns related to higher $\mathrm{PaCO}_{2}$ levels include increased cerebral oedema, respiratory acidosis and impaired right ventricular function, which may all contribute to poor outcomes [11-13].

Regarding oxygen, experimental studies have shown that exposure to very high levels of arterial oxygen tension $\left(\mathrm{PaO}_{2}\right)$ during post-resuscitation care may increase ROS production and exacerbate the developing neurological damage [14]. Indeed, in retrospective and observational human studies, severe hyperoxia $\left(\mathrm{PaO}_{2}>40 \mathrm{kPa}\right)$ has been associated with poor outcome after cardiac arrest [15-19]. In contrast, moderate hyperoxia during post-resuscitation intensive care has been associated with better long-term neurological recovery and improved organ function [20]. A retrospective analysis from one large intensive care unit (ICU) registry suggested that the $\mathrm{PaO}_{2}$ associated with the lowest mortality was around $20 \mathrm{kPa}$ [21].

In mechanically ventilated patients, both $\mathrm{PaCO}_{2}$ and $\mathrm{PaO}_{2}$ can be altered via the ventilator settings [22]. Currently there are limited high-quality data on the optimal carbon dioxide and oxygen targets in cardiac arrest patients. Accordingly, we performed a multicentre, randomised pilot trial to assess the feasibility and the effect on the serum concentration of NSE of targeting low-normal or high-normal $\mathrm{PaCO}_{2}$ and normoxia or moderate hyperoxia after OHCA and successful resuscitation. In addition, we investigated the effect of these interventions on other markers of neurological and cardiac injury, electroencephalography (EEG) and cerebral oxygenation. Our hypothesis was that targeting highnormal $\mathrm{PaCO}_{2}$ and moderate hyperoxia would result in lower NSE concentrations at $48 \mathrm{~h}$ after cardiac arrest.

\section{Methods \\ Trial design}

The full details of the Carbon dioxide, Oxygen and Mean arterial pressure After Cardiac Arrest and REsuscitation (COMACARE) study have been previously described [23]. In brief, we conducted a prospective, multicentre, randomised trial with a $2^{3}$ factorial design. A total of 123 unconscious, mechanically ventilated patients resuscitated from OHCA were randomly assigned to intervention targets of low-normal or high-normal $\mathrm{PaCO}_{2}$, normoxia or moderate hyperoxia and low-normal or high-normal mean arterial pressure (MAP) for the first $36 \mathrm{~h}$ in the intensive care unit (ICU). Each patient was randomised into one of eight arms with each arm having a different combination of targets for $\mathrm{PaCO}_{2}, \mathrm{PaO}_{2}$ and MAP. In this paper we report the results of the low-normal vs. high-normal $\mathrm{PaCO}_{2}$ and the normoxia vs. moderate hyperoxia comparisons.

\section{Participants}

We included adult patients resuscitated from witnessed OHCA of presumed cardiac origin with ventricular fibrillation (VF) or ventricular tachycardia (VT) as the initial rhythm. For details regarding the inclusion and exclusion criteria, the participating centres, the informed consent and the ethical approval, please see the electronic supplemental material (ESM).

\section{Interventions}

After ICU admission and randomisation, we directed the treating personnel to target low-normal (4.5-4.7 $\mathrm{kPa})$ or high-normal $(5.8-6.0 \mathrm{kPa}) \mathrm{PaCO}_{2}$ by adjusting the minute ventilation (tidal volume and ventilation rate) delivered by the ventilator. Normoxia $(10-15 \mathrm{kPa})$ or 
moderate hyperoxia ( $20-25 \mathrm{kPa}$ ) were targeted by adjusting $\mathrm{FiO}_{2}$ and PEEP levels on the ventilator. Laminated signs designating the intervention targets were used at the patients' bedsides and on the ventilators. The ventilator adjustments were guided by arterial blood gas (ABG) analyses (corrected to each patient's actual temperature) performed at least every $3 \mathrm{~h}$. We used end-tidal carbon dioxide $\left(\mathrm{EtCO}_{2}\right)$ value as an additional guide in targeting the desired $\mathrm{PaCO}_{2}$ level. In the normoxia group, we used peripheral oxygen saturation $\left(\mathrm{SpO}_{2}\right)$ as an additional guide, targeting an $\mathrm{SpO}_{2}$ value of 95-98\%. A volumecontrolled or a pressure-controlled ventilation mode was used according to the treating clinician's preference. We continued the intervention for $36 \mathrm{~h}$ from the ICU admission or until the patient was extubated or ventilation was set to a spontaneous mode, whichever occurred first. All patients received targeted temperature management (TTM) at $33{ }^{\circ} \mathrm{C}$ or $36{ }^{\circ} \mathrm{C}$ and were sedated according to the treating clinicians' instructions. All patients received standard care, monitoring and assessments based on the protocol of the ICU, including direct blood pressure monitoring via an arterial catheter.

\section{Outcomes}

The primary outcome was the NSE serum concentration at $48 \mathrm{~h}$ after cardiac arrest. The main feasibility outcomes were the differences in $\mathrm{PaCO}_{2}$ and $\mathrm{PaO}_{2}$ between the groups targeting low-normal (4.5-4.7 kPa) and high-normal (5.8-6.0 kPa) $\mathrm{PaCO}_{2}$ and normoxia (10-15 kPa) and moderate hyperoxia $(20-25 \mathrm{kPa})$, respectively. The prespecified secondary outcomes were NSE serum concentrations at 24 and $72 \mathrm{~h}$ after cardiac arrest; S100B protein (a biomarker of glial injury) serum concentrations at 24, 48 and $72 \mathrm{~h}$ after cardiac arrest; cardiac troponin (TnT) plasma concentrations at 24,48 and $72 \mathrm{~h}$ after cardiac arrest; regional frontal cerebral oxygenation $\left(\mathrm{rSO}_{2}\right)$ measured by continuous near-infrared spectroscopy (NIRS) monitoring during the first $48 \mathrm{~h}$ after admission to the ICU; results of continuous EEG monitoring for the first $48 \mathrm{~h}$ after admission to the ICU interpreted by an experienced senior neurophysiologist blinded to study group allocation; neurological recovery assessed with Cerebral Performance Category (CPC) at 6 months after cardiac arrest (CPC 1-2 considered a good outcome, and CPC 3-5 a poor outcome) determined by an experienced neurologist blinded to study group allocation; total duration of intensive care; total duration of mechanical ventilation; length of hospital stay; discharge destination and vital status at 30 days after cardiac arrest (dead or alive). Other feasibility outcomes included distribution of values for primary and secondary outcomes, randomised/ screened patient ratio, consent rate, data completion rate and recruitment duration. The predefined serious adverse events (SAE) that could be related to the interventions were severe hypercapnia and respiratory acidosis $\left(\mathrm{PaCO}_{2}>10 \mathrm{kPa}\right.$ and $\left.\mathrm{pH}<7.15\right)$, unexplained brain oedema on $\mathrm{CT}$ scanning and severe ARDS $\left(\mathrm{PaO}_{2} / \mathrm{FiO}_{2}\right.$ ratio of $<100 \mathrm{mmHg}$ ).

\section{Data collection, randomisation and statistical methods}

The data collection and laboratory methods, randomisation procedure and statistical analysis are described in detail in the ESM.

\section{Results}

For the flowcharts demonstrating patient enrolment and group allocations, please see the ESM (Fig. 1a,b). The first patient was randomised on 22 March 2016, and recruitment was completed by 3 November 2017. The 6-month follow-up of the last patient was completed by 3 May 2018. The baseline characteristics and resuscitation factors were comparable between the groups (Table 1). We observed a clear separation during the intervention in $\mathrm{PaCO}_{2}$ between the low-normal and the high-normal $\mathrm{PaCO}_{2}$ groups and in $\mathrm{PaO}_{2}$ between the normoxia and the moderate hyperoxia groups (Fig. 1). The median (interquartile range $[\mathrm{IQR}]$ ) expiratory tidal volume per body weight and the median (IQR) ventilation rate were $5.8 \mathrm{ml} / \mathrm{kg}(5.2-6.8 \mathrm{ml} / \mathrm{kg})$ and $12 \mathrm{~min}^{-1}\left(12-14 \mathrm{~min}^{-1}\right)$ in the low-normal $\mathrm{PaCO}_{2}$ group and $5.4 \mathrm{ml} / \mathrm{kg}(4.8-5.9 \mathrm{ml} /$ $\mathrm{kg})$ and $11 \mathrm{~min}^{-1}\left(10-12 \mathrm{~min}^{-1}\right)$ in the high-normal $\mathrm{PaCO}_{2}$ group, respectively. The median (IQR) $\mathrm{FiO}_{2}$ and PEEP levels were $35 \%(30-40 \%)$ and $7.2 \mathrm{cmH}_{2} \mathrm{O}(6.2-$ $\left.8.2 \mathrm{cmH}_{2} \mathrm{O}\right)$ in the normoxia group and $50 \%(45-59 \%)$ and $8.2 \mathrm{cmH}_{2} \mathrm{O}\left(6.3-10.0 \mathrm{cmH}_{2} \mathrm{O}\right)$ in the moderate hyperoxia group, respectively.

We did not find significant differences in the median serum NSE concentration at $48 \mathrm{~h}$ after cardiac arrest between the intervention groups (in the low-normal $\mathrm{PaCO}_{2}$ group, $18.8 \mu \mathrm{g} / \mathrm{l}$ [IQR $13.9-28.3 \mu \mathrm{g} / \mathrm{l}$ ] and in the high-normal $\mathrm{PaCO}_{2}$ group, $22.5 \mu \mathrm{g} / \mathrm{l}$ [IQR 14.2$34.9 \mu \mathrm{g} / \mathrm{l}], p=0.400$; in the normoxia group, $22.3 \mu \mathrm{g} / \mathrm{l}$ [IQR, 14.8-27.8 $\mu \mathrm{g} / \mathrm{l}]$ and in the moderate hyperoxia group, $20.6 \mu \mathrm{g} / \mathrm{l}[\mathrm{IQR}, 14.2-34.9 \mu \mathrm{g} / \mathrm{l}], p=0.594)$. The NSE, S100B and TnT concentrations were also comparable over time in the low-normal $\mathrm{PaCO}_{2}$ and high-normal $\mathrm{PaCO}_{2}$ groups and the normoxia and moderate hyperoxia groups (Figs. 2, 3, 4).

The median cerebral oxygen saturation $\left(\mathrm{rSO}_{2}\right)$ was significantly higher in the high-normal $\mathrm{PaCO}_{2}$ group than in the low-normal $\mathrm{PaCO}_{2}$ group, $p<0.001$ (Fig. 5a). In addition, the $\mathrm{rSO}_{2}$ was significantly higher in the moderate hyperoxia group than in the normoxia group, $p<0.001$ (Fig. 5b). We found no significant differences between any of the groups regarding mortality at 30 days after cardiac arrest, good neurological 
Table 1 Baseline characteristics of the study population

\begin{tabular}{|c|c|c|c|c|}
\hline & $\begin{array}{l}\text { Low-normal } \\
\mathrm{PaCO}_{2} \text { group } \\
(n=61)\end{array}$ & $\begin{array}{l}\text { High-normal } \\
\mathrm{PaCO}_{2} \text { group } \\
(n=59)\end{array}$ & Normoxia group $(n=61)$ & $\begin{array}{l}\text { Moderate } \\
\text { hyperoxia group } \\
(n=59)\end{array}$ \\
\hline \multicolumn{5}{|l|}{ Demographic characteristics } \\
\hline Age, mean $\pm S D$, years & $58 \pm 11$ & $61 \pm 15$ & $59 \pm 13$ & $60 \pm 14$ \\
\hline Male sex, $n(\%)$ & $53(87)$ & $45(76)$ & $50(82)$ & $48(81)$ \\
\hline Weight, mean $\pm S D$, kg & $86 \pm 17$ & $83 \pm 16$ & $83 \pm 15$ & $86 \pm 18$ \\
\hline \multicolumn{5}{|l|}{ Neurologic function before cardiac arrest } \\
\hline Normal, CPC score 1, n (\%) & $56(92)$ & $55(93)$ & $56(92)$ & $55(93)$ \\
\hline Some disability, CPC core 2, n (\%) & $5(8)$ & $4(7)$ & $5(8)$ & $4(7)$ \\
\hline \multicolumn{5}{|l|}{ Medical history } \\
\hline Antihypertensive medication, $n(\%)$ & $27(44)$ & $33(56)$ & $31(51)$ & $29(49)$ \\
\hline Chronic heart failure (NYHA class IV), $n(\%)^{a}$ & $2(3)$ & 0 & $2(3)$ & $0(0)$ \\
\hline Inhaled corticosteroids, n (\%) & $1(2)$ & $5(8)$ & $5(8)$ & $1(2)$ \\
\hline Inhaled bronchodilators, $n$ (\%) & $2(3)$ & $6(10)$ & $5(8)$ & $3(5)$ \\
\hline Smoker, $n(\%)^{b}$ & $25(41)$ & $15(25)$ & $19(31)$ & $21(36)$ \\
\hline \multicolumn{5}{|l|}{ Cardiac arrest location } \\
\hline Home, $n(\%)$ & $34(56)$ & $26(44)$ & $33(54)$ & $27(46)$ \\
\hline Public place, $n(\%)$ & $27(44)$ & $33(56)$ & $28(46)$ & $32(54)$ \\
\hline \multicolumn{5}{|l|}{ Resuscitation factors } \\
\hline Bystander-initiated resuscitation, $n(\%)$ & $50(82)$ & $48(81)$ & $50(82)$ & $48(81)$ \\
\hline Time to basic life support ${ }^{\mathrm{c}}$, median (IQR), min & $7(5-9)$ & $8(6-10)$ & $7(6-10)$ & $7(6-9)$ \\
\hline Time to advanced life support, median (IQR), min & $9(7-12)$ & $10(8-13)$ & $10(8-12)$ & $10(7-12)$ \\
\hline Time to ROSC, median (IQR), min & $20(16-25)$ & $21(17-26)$ & $20(16-25)$ & $21(16-27)$ \\
\hline Intubated during resuscitation, $n(\%)$ & $30(49)$ & $27(46)$ & $28(46)$ & $29(49)$ \\
\hline \multicolumn{5}{|l|}{ Immediate interventional cardiology } \\
\hline Prehospital thrombolysis, $n(\%)$ & $2(3)$ & $2(3)$ & $2(3)$ & $2(3)$ \\
\hline Coronary angiography before ICU admission, $n$ (\%) & $31(51)$ & $32(54)$ & $35(57)$ & $28(47)$ \\
\hline \multicolumn{5}{|l|}{ Clinical status on ICU admission } \\
\hline GCS after ROSC, median (IQR) ${ }^{\mathrm{d}}$ & $3(3-3)$ & $3(3-3)$ & $3(3-3)$ & $3(3-3)$ \\
\hline APACHE II score, median (IQR) & $27(24-30)$ & $29(25-33)$ & $27(24-31)$ & $28(25-31)$ \\
\hline Prehospital cooling, $n(\%)$ & $5(8)$ & $5(8)$ & $3(5)$ & $7(12)$ \\
\hline Dose of norepinephrine, mean $\pm S D, \mu g / k g / m i n$ & $0.07 \pm 0.1$ & $0.07 \pm 0.1$ & $0.07 \pm 0.1$ & $0.07 \pm 0.1$ \\
\hline Time from ROSC to randomisation, median (IQR), min & $159(130-204)$ & $180(143-216)$ & $178(139-216)$ & $166(135-192)$ \\
\hline \multicolumn{5}{|l|}{ Targeted temperature management } \\
\hline $33^{\circ} \mathrm{C}, n(\%)$ & $43(70)$ & $40(68)$ & $41(67)$ & $42(71)$ \\
\hline $36^{\circ} \mathrm{C}, n(\%)$ & $18(30)$ & $19(32)$ & $20(33)$ & $17(29)$ \\
\hline
\end{tabular}

$\mathrm{PaCO}_{2}$ arterial carbon dioxide tension, $S D$ standard deviation, IQR interquartile range, $C P C$ Cerebral Performance Category [1, good cerebral performance (normal life); 2, moderate cerebral disability (disabled but independent); 3, severe cerebral disability (conscious but disabled and dependent); 4 , coma or vegetative state (unconscious); 5, brain death], NYHA New York Heart Association, CPR cardiopulmonary resuscitation, ICU intensive care unit, GCS Glasgow coma scale, ROSC return of spontaneous circulation, $A P A C H E$ acute physiology and chronic health evaluation

a Data missing for 2 patients

b Data missing for 13 patients

c The time for a paramedic unit with BLS equipment and skills to reach the patient

d Data missing for 9 patients

recovery $(\mathrm{CPC} 1-2)$ at 6 months after cardiac arrest, the duration of intensive care or mechanical ventilation, or the frequency of the predefined SAEs (Table 2). The EEG grading at the ICU admission and the end of the intervention was also similar in all groups (Table 3). Regarding the NSE results at $48 \mathrm{~h}$ after cardiac arrest or good neurological outcomes at 6 months, we did not find any significant interactions between the $\mathrm{PaCO}_{2}$, $\mathrm{PaO}_{2}$, MAP or TTM targets (ESM Table 4). 

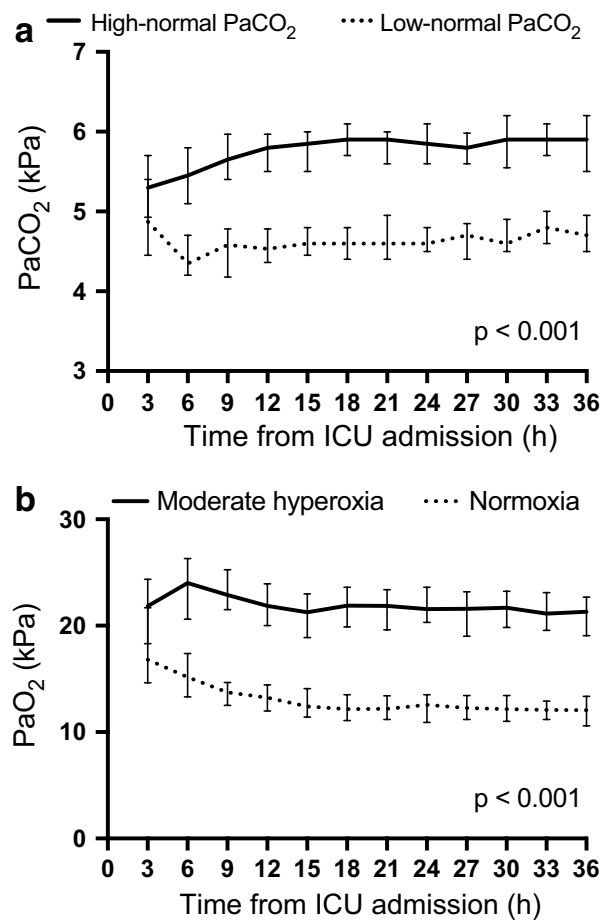

Fig. 1 Median (interquartile range) a $\mathrm{PaCO}_{2}$ during the intervention in the low-normal and high-normal $\mathrm{PaCO}_{2}$ groups. $\mathbf{b} \mathrm{PaO}_{2}$ during the intervention in the normoxia and moderate hyperoxia groups

\section{Discussion}

In this prospective, randomised trial, we found that targeting a specific level of $\mathrm{PaCO}_{2}$ or $\mathrm{PaO}_{2}$ was feasible in comatose, mechanically ventilated patients after cardiac arrest. However, these interventions did not change the concentration of NSE at $48 \mathrm{~h}$ after cardiac arrest or any of the measured markers of neurological or cardiac injury. Targeting high-normal $\mathrm{PaCO}_{2}$ or moderate hyperoxia both increased cerebral oxygenation measured by NIRS, but the implications of this are unclear. The preliminary results of the current trial cannot confirm or refute a benefit or harm within the studied carbon dioxide and oxygen ranges.

We chose to use two markers of cerebral injury in this trial. NSE is a cytoplasmic glycolytic enzyme found in neurons and neuroectodermal cells, and S100B is a protein specific to neuroglial cells. Both are released into the cerebrospinal fluid and bloodstream after neuronal damage, and their concentrations during the first 24-72 $\mathrm{h}$ after cardiac arrest correlate with the severity of the brain injury and the probability of a poor outcome [24-27]. We chose the NSE concentration at $48 \mathrm{~h}$ as the primary outcome because it is well documented as a surrogate marker of HIE and it has an established role in the multimodal prognostication of the OHCA patients [28]. The
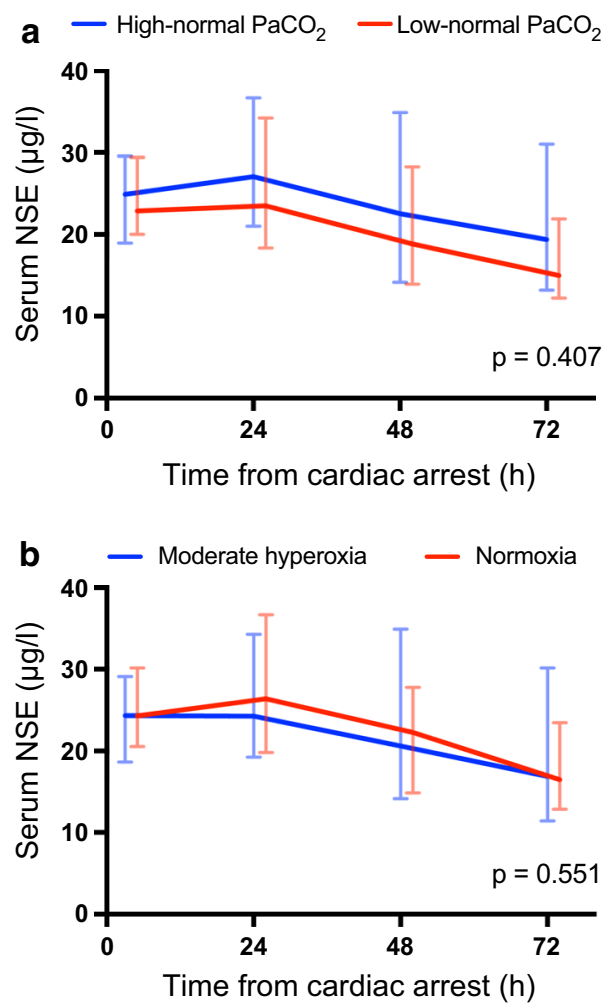

Fig. 2 Baseline, $24 \mathrm{~h}, 48 \mathrm{~h}$ and $72 \mathrm{~h}$ median (interquartile range) serum neuron-specific enolase (NSE) concentrations for patients allocated to targeting a low-normal and high-normal $\mathrm{PaCO}_{2}$, b normoxia and moderate hyperoxia

similar levels of these surrogate markers in all intervention groups of our study suggest that targeting higher or lower $\mathrm{PaCO}_{2}$ within the normal range or moderately elevated $\mathrm{PaO}_{2}$ instead of normoxia does not markedly affect the development of HIE in post cardiac arrest patients. Compared to previous trials [10, 29], the NSE concentrations in our study were lower and already decreasing at $48 \mathrm{~h}$ after cardiac arrest. This is likely explained by our relatively strict inclusion criteria.

It is thought that the development of the HIE begins early after the ROSC and for this reason the interventions aiming at affecting its course should be started as early as possible. For practical reasons, targeting specific levels of $\mathrm{PaCO}_{2}$ and $\mathrm{PaO}_{2}$ is difficult during prehospital care. Thus, we decided to start the interventions immediately after ICU admission at the hospital. Moreover, we think that the delay between the ROSC and the beginning of the interventions was acceptable for most participants (Table 1). However, it is possible that the potential effect of the interventions was decreased as a result of the delay.

This trial was not powered for mortality or neurologic outcome and the results based on a surrogate marker of brain injury cannot exclude benefits or harms from 

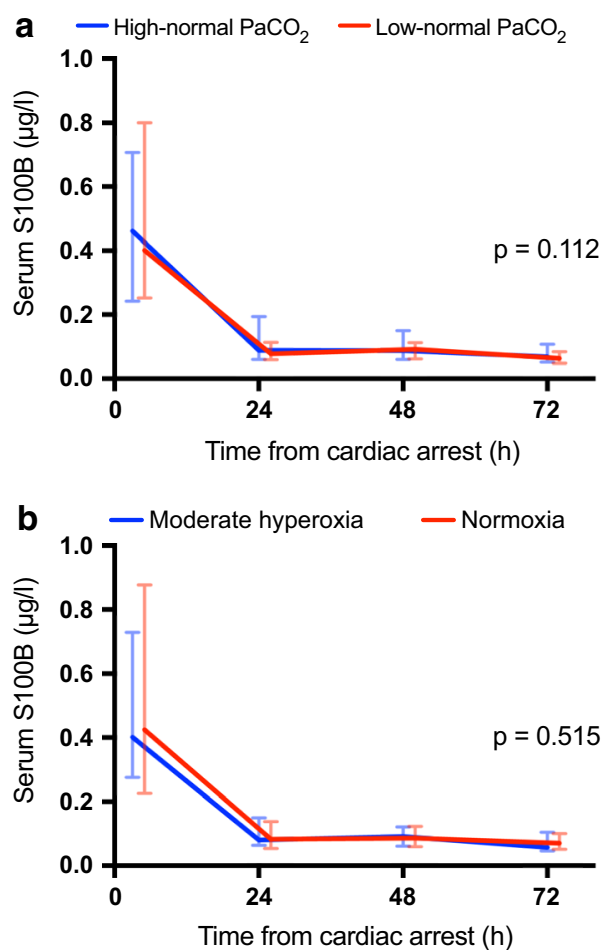

Fig. 3 Baseline, $24 \mathrm{~h}, 48 \mathrm{~h}$ and $72 \mathrm{~h}$ median (interquartile range) serum $\mathrm{S100B}$ concentrations for patients allocated to targeting a lownormal and high-normal $\mathrm{PaCO}_{2}$, b normoxia and moderate hyperoxia

different levels of $\mathrm{PaCO}_{2}$ within the normal range or moderate hyperoxia after cardiac arrest. The results of our study support the safety and feasibility of studying the effects of these interventions in a larger trial. However, because the NSE results were so similar between the intervention groups, it might be more worthwhile to look into the effect of different levels of $\mathrm{PaCO}_{2}$ and $\mathrm{PaO}_{2}$ instead. A larger randomised trial comparing mild hypercapnia $(6.7-7.3 \mathrm{kPa})$ with normocapnia is already taking place (NCT03114033). There is an imminent need for large trials on the long-term effects of different oxygen targets in patients after cardiac arrest and other forms of neurocritical illness [30].

The effect of $\mathrm{PaCO}_{2}$ may differ according to the target temperature during TTM, and hypocapnia may be especially common in patients treated with a target temperature of $33^{\circ} \mathrm{C}$ [31]. Cerebrovascular reactivity is maintained during therapeutic hypothermia, and hypocapnia may cause decreased cerebral blood flow and ischaemia in these patients. Regarding oxygen, in the only randomised study performed on the use of oxygen in cardiac arrest patients, an increase in NSE within a subgroup of patients exposed to $100 \%$ oxygen and not treated with TTM at $33{ }^{\circ} \mathrm{C}$ was seen [32]. This may indicate harmful effects of extreme hyperoxia on the developing HIE especially in patients without the attenuating effect of
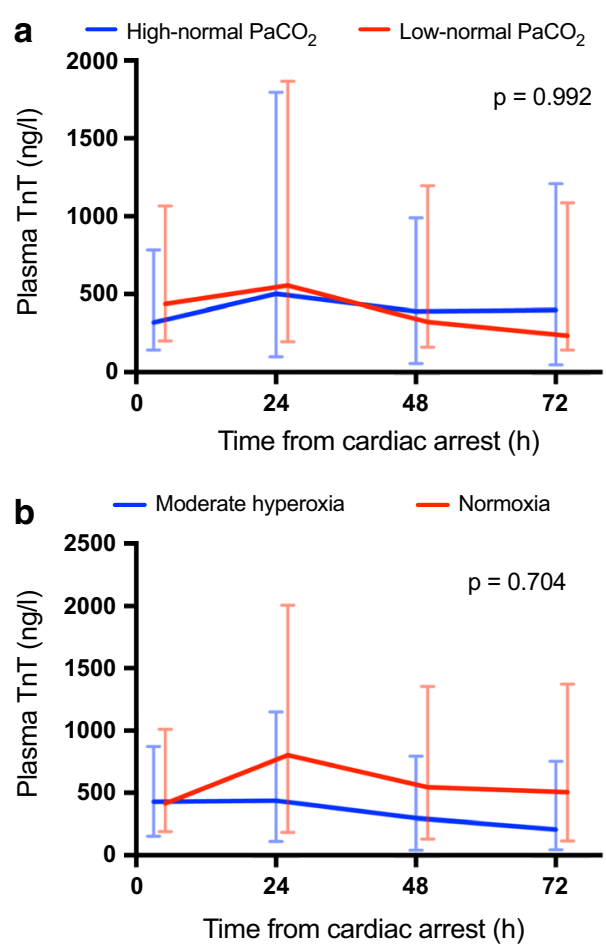

Fig. 4 Baseline, $24 \mathrm{~h}, 48 \mathrm{~h}$ and $72 \mathrm{~h}$ median (interquartile range) plasma cardiac troponin (TnT) concentrations for patients allocated to targeting a low-normal and high-normal $\mathrm{PaCO}_{2}$, $\mathbf{b}$ normoxia and moderate hyperoxia

hypothermia. Indeed, the results of one large registry study suggested no association between oxygen and survival in OHCA patients predominantly treated with hypothermia [17]. We, however, included patients treated with TTM targets of both $33{ }^{\circ} \mathrm{C}$ and $36^{\circ} \mathrm{C}$ and found no interaction between temperature and neither carbon dioxide nor oxygen targets.

We found that high-normal $\mathrm{PaCO}_{2}$ and moderate hyperoxia resulted in higher cerebral oxygen saturation when compared with low-normal $\mathrm{PaCO}_{2}$ and normoxia, respectively. Higher $\mathrm{rSO}_{2}$ may reflect improved oxygen delivery, and there are some data suggesting that higher $\mathrm{rSO}_{2}$ is related to better outcome after cardiac arrest [33]. Recently, Taccone and colleagues showed a moderate relationship between cerebral perfusion pressure and $\mathrm{rSO}_{2}$ in OHCA patients undergoing TTM [34]. Nevertheless, the relationship between $\mathrm{rSO}_{2}, \mathrm{CBF}$ and outcome is not fully understood. Combining continuous transcranial Doppler ultrasound with NIRS would likely have provided additional information of the CBF. However, for practical reasons, it was not possible to implement in this multicentre trial.

In experimental studies, $\mathrm{CO}_{2}$ has exhibited potent anticonvulsive properties [7]. In patients with subarachnoid 
haemorrhage, there appears to be an association between invasively measured low levels of oxygen in brain tissue and periodical epileptic discharges [35]. In this pilot trial, we did not find any association between the targeted carbon dioxide or oxygen level and EEG abnormalities. Considering the relatively small absolute difference in $\mathrm{PaCO}_{2}$ between the groups, this study may not have been powered to exclude an anticonvulsive effect of high-normal $\mathrm{PaCO}_{2}$ or different oxygen levels.

Cardiac arrest and resuscitation result in global ischaemia-reperfusion injury which affects the heart and may lead to myocardial stunning and haemodynamic instability [36]. Moreover, this myocardial ischaemia-reperfusion damage may be aggravated by myocardial infarction because acute coronary syndrome (ACS) is the most common cause of OHCA. Hypercapnia has been related to impaired right ventricular function and acidosis which may negatively affect the recovery of critically ill neurologic patients [12]. The results of two large trials investigating the effect of hyperoxia on myocardial injury in ACS patients were controversial $[37,38]$. There are no previous data from randomised trials on the effect of different levels of $\mathrm{PaCO}_{2}$ or moderate hyperoxia on myocardial damage after cardiac arrest and resuscitation. We found that the concentration of TnT was comparable in the two $\mathrm{PaCO}_{2}$ groups as well as in the two $\mathrm{PaO}_{2}$ groups during the first $72 \mathrm{~h}$ after cardiac arrest.

Our trial has several strengths. First, the study protocol, including the plan for the statistical analysis, had been previously published [23]. Second, by using relatively strict eligibility criteria, the study was focused on a homogenous group of OHCA patients, thereby reducing the bias caused by differences in baseline characteristics and resuscitation factors. Third, we carried out post-resuscitation intensive care according to the current guidelines for all patients. Fourth, we studied patients in multiple centres in two countries. Fifth, we took frequent ABG samples and used continuous $\mathrm{EtCO}_{2}$ and $\mathrm{SpO}_{2}$ monitoring to ensure that $\mathrm{PaCO}_{2}$ and $\mathrm{PaO}_{2}$ remained at the target level for the whole intervention period. Finally, we recorded frontal $\mathrm{rSO}_{2}$ and EEG continuously during the whole intervention.

This study also has some limitations. First, although we conducted a multicentre trial, most participants were recruited at one hospital. Second, because the $\mathrm{PaCO}_{2}$, $\mathrm{PaO}_{2}, \mathrm{EtCO}_{2}$ and $\mathrm{SpO}_{2}$ are routinely monitored variables in the ICU, the study intervention could not be blinded; thus, the treating personnel were aware of the study

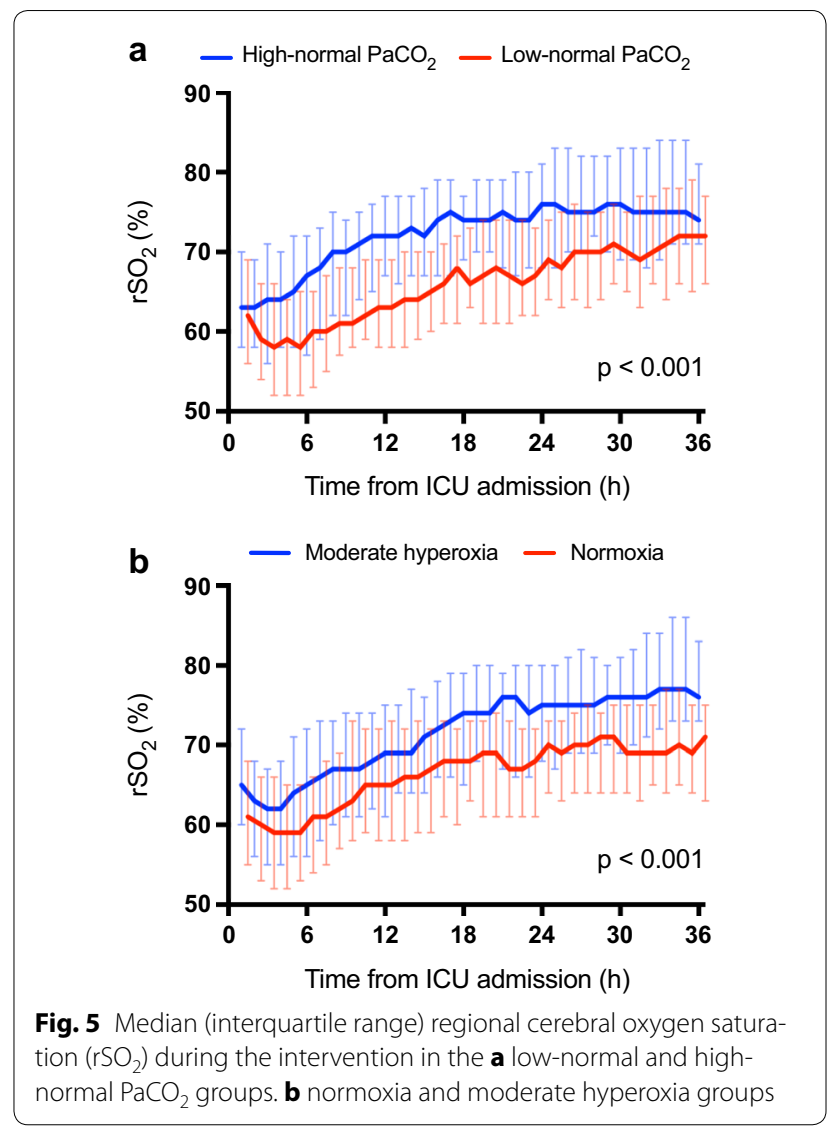

group allocations. Third, we used a four-channel technique for EEG monitoring. There is a risk that some focal epileptic discharges may have been undetected. Finally, the blood samples taken at the Danish site had to be analysed on-site for logistical reasons. However, to minimise a possible bias resulting from technical issues, the same laboratory kits for NSE and S100B evaluation were used in both Finland and Denmark.

\section{Conclusions}

Targeting low-normal or high-normal $\mathrm{PaCO}_{2}$ and normoxia or moderate hyperoxia was feasible in comatose mechanically ventilated patients admitted to the ICU after OHCA and resuscitation. The target levels of $\mathrm{PaCO}_{2}$ or $\mathrm{PaO}_{2}$ did not affect the serum concentration of NSE at $48 \mathrm{~h}$. High-normal $\mathrm{PaCO}_{2}$ and moderate hyperoxia resulted in better cerebral oxygen saturation which may indicate higher $\mathrm{CBF}$ and oxygen delivery, but the clinical implications of these findings are unclear. 
Table 2 Primary and secondary outcomes after the intervention

\begin{tabular}{|c|c|c|c|c|c|c|}
\hline & $\begin{array}{l}\text { Low-normal } \\
\mathrm{PaCO}_{2} \text { group } \\
(n=61)\end{array}$ & $\begin{array}{l}\text { High-normal } \\
\mathrm{PaCO}_{2} \text { group } \\
(n=59)\end{array}$ & $P$ value & Normoxia group $(n=61)$ & $\begin{array}{l}\text { Moderate } \\
\text { hyperoxia group } \\
(n=59)\end{array}$ & $P$ value \\
\hline \multicolumn{7}{|l|}{ Primary outcome } \\
\hline $\begin{array}{l}\text { Median (IQR) NSE at } 48 \mathrm{~h} \text { after cardiac } \\
\text { arrest, } \mu \mathrm{g} / \mathrm{l}^{\mathrm{a}}\end{array}$ & $18.8(13.9-28.3)$ & $22.6(14.8-34.9)$ & 0.290 & $22.4(14.8-28.3)$ & $20.6(14.2-34.9)$ & 0.649 \\
\hline \multicolumn{7}{|c|}{ Secondary outcomes } \\
\hline \multicolumn{7}{|c|}{ Neurologic recovery at 6 months after cardiac arrest } \\
\hline Good, CPC score 1-2,n (\%) & $43(71)$ & $35(59)$ & 0.200 & $42(69)$ & $36(61)$ & 0.368 \\
\hline $\begin{array}{l}\text { Mortality } 30 \text { days after cardiac arrest, } \\
n(\%)\end{array}$ & $15(25)$ & $23(39)$ & 0.090 & $18(30)$ & $20(34)$ & 0.605 \\
\hline $\begin{array}{l}\text { Median (IQR) duration of intensive } \\
\text { care, } h^{b}\end{array}$ & $92(66-136)$ & $104(79-147)$ & 0.120 & $97(73-140)$ & $100(76-143)$ & 0.810 \\
\hline $\begin{array}{l}\text { Median (IQR) duration of mechanical } \\
\text { ventilation, } h^{c}\end{array}$ & $63(47-97)$ & $75(52-110)$ & 0.589 & $61(47-95)$ & $74(52-115)$ & 0.211 \\
\hline \multicolumn{7}{|l|}{ Severe adverse events } \\
\hline $\begin{array}{l}\text { Severe hypercapnia and respiratory aci- } \\
\text { dosis }\left(\mathrm{PaCO}_{2}>10 \mathrm{kPa} \text { and } \mathrm{pH}<7.15\right) \\
n(\%)\end{array}$ & $0(0)$ & $1(2)$ & 0.307 & $1(2)$ & $0(0)$ & 0.323 \\
\hline $\begin{array}{l}\text { Unexplained brain oedema on CT } \\
\text { scanning, } n(\%)\end{array}$ & $0(0)$ & $1(2)$ & 0.307 & $1(2)$ & $0(0)$ & 0.323 \\
\hline $\begin{array}{l}\text { Severe ARDS }\left(\mathrm{PaO}_{2} / \mathrm{FiO}_{2}<100 \mathrm{mmHg}\right) \\
n(\%)\end{array}$ & $0(0)$ & $2(3)$ & 0.147 & $1(2)$ & $1(2)$ & 0.981 \\
\hline
\end{tabular}

$\mathrm{PaCO}_{2}$ arterial carbon dioxide tension, IQR interquartile range, NSE neuron-specific enolase, CPC cerebral performance category [1, good cerebral performance (normal life); 2, moderate cerebral disability (disabled but independent); 3 , severe cerebral disability (conscious but disabled and dependent); 4 , coma or vegetative state (unconscious); 5, brain death], $C T$ computed tomography, $A R D S$ acute respiratory distress syndrome, $\mathrm{FiO}_{2}$ fraction of inspired oxygen

a Data missing for 1 patient

${ }^{b}$ Data missing for 6 patients

c Data missing for 3 patients

Table 3 EEG grading in the low-normal and high normal $\mathrm{PaCO}_{2}$ groups at ICU admission and at the end of the intervention

\begin{tabular}{|c|c|c|c|c|c|c|c|c|}
\hline \multirow[t]{2}{*}{ EEG grade ${ }^{a}$} & \multicolumn{4}{|l|}{ ICU admission } & \multicolumn{4}{|c|}{ End of intervention } \\
\hline & Low-normal $\mathrm{PaCO}_{2}$ & $\begin{array}{l}\text { High-nor- } \\
\text { mal } \mathrm{PaCO}_{2}\end{array}$ & Normoxia & $\begin{array}{l}\text { Moderate } \\
\text { hyperoxia }\end{array}$ & $\begin{array}{l}\text { Low-normal } \\
\mathrm{PaCO}_{2}\end{array}$ & $\begin{array}{l}\text { High-normal } \\
\mathrm{PaCO}_{2}\end{array}$ & Normoxia & $\begin{array}{l}\text { Moderate } \\
\text { hyperoxia }\end{array}$ \\
\hline 1 & $17(29)$ & $14(24)$ & $19(32)$ & $12(20)$ & $43(73)$ & $35(59)$ & $43(73)$ & $35(59)$ \\
\hline 2 & $3(5)$ & $2(3)$ & $1(2)$ & $4(7)$ & $3(5)$ & $4(7)$ & $4(7)$ & $3(5)$ \\
\hline \multirow[t]{2}{*}{3} & $39(66)$ & $43(73)$ & $39(66)$ & $43(73)$ & $13(22)$ & $20(34)$ & $12(20)$ & $21(36)$ \\
\hline & $p=0.710$ & & $p=0.167$ & & $p=0.294$ & & $p=0.181$ & \\
\hline
\end{tabular}

Data are presented as $n(\%)$ of patients

EEG electroencephalography, $\mathrm{PaCO}_{2}$ arterial carbon dioxide tension, ICU intensive care unit

${ }^{\text {a }}$ EEG grading system for continuous EEG findings following cardiac arrest according to Crepeau et al.: mild (grade 1), moderate (grade 2) and severe (grade 3)

\section{Other information}

\section{Protocol}

The protocol of the COMACARE study has been previously published [23].

\section{Electronic supplementary material}

The online version of this article (https://doi.org/10.1007/s00134-018-5453-9) contains supplementary material, which is available to authorized users.

\section{Author details}

${ }^{1}$ Department of Anaesthesiology, Intensive Care and Pain Medicine, University of Helsinki and Helsinki University Hospital, Helsinki, Finland. ${ }^{2}$ Department of Intensive Care, North Karelia Central Hospital, Joensuu, Finland. ${ }^{3}$ Department of Intensive Care, Päijät-Häme Central Hospital, Lahti, Finland. ${ }^{4}$ Department of Anaesthesia and Intensive Care, Päijät-Häme Central Hospital, Lahti, Finland. ${ }^{5}$ Department of Neurology, University of Helsinki and Helsinki University Hospital, Helsinki, Finland. ${ }^{6}$ Clinical Neurophysiology, HUS Medical Imaging Center, University of Helsinki and Helsinki University Hospital, Helsinki, Finland. ${ }^{7}$ Department of Intensive Care, Kuopio University Hospital, 
Kuopio, Finland. ${ }^{8}$ Aarhus University Hospital, Aarhus, Denmark. ${ }^{9}$ Department of Anaesthesia and Intensive Care, Central Finland Central Hospital, Jyväskylä, Finland. ${ }^{10}$ Department of Emergency Medicine and Services, University of Helsinki and Helsinki University Hospital, Helsinki, Finland.

\section{Acknowledgements}

Open access funding provided by University of Helsinki including Helsinki University Central Hospital. COMACARE STUDY GROUP. Aarhus University Hospital: Thomas Birkelund, Susanne Ilkjaer, Hans Kirkegaard; Central Finland Central Hospital: Raili Laru-Sompa, Anni Pulkkinen, Mikko Reilama, Sinikka Tolmunen; Helsinki University Hospital: Minna Bäcklund, Jonna Heinonen, Johanna Hästbacka, Pekka Jakkula, Nina Lundblom, Marcus Norrgård, Marjatta Okkonen, Ville Pettilä, Markus B Skrifvars, Tarja Suhonen, Marjaana Tiainen, Tuukka Tikka, Marjut Timonen, Jussi Toppila, Miia Valkonen, Erika Wilkman; Jorvi Hospital:Teemu Hult, Tuomas Oksanen; Kuopio University Hospital: Stepani Bendel, Elina Halonen, Sari Rahikainen, Saija Rissanen, Eija Vaskelainen; North Karelia Central Hospital:Tanja Eiserbeck, Sirkku Heino, Helena Jyrkönen, Matti Reinikainen, Johanna Räsänen, Tero Surakka; Päijät-Häme Central Hospital: Talvikki Koskue, Petteri Kujala, Pekka Loisa, Marika Lähde; Tampere University Hospital: Jari Kalliomäki, Sari Karlsson, Atte Kukkurainen, Simo Varila. We thank Tuomas Selander, MSc, biostatistician, for help with the statistical analyses.

\section{Funding}

Independent funding support has been received from Helsinki University; Helsinki University Hospital (State funding, Finland); Stiftelsen Dorothea Olivia, Karl Walter och Jarl Walter Perkléns minne; The Laerdal Foundation for Acute Medicine; Medicinska Understödsföreningen Liv och Hälsa; Finska Läkaresällskapet; The Finnish Society of Anaesthesiologists; Orion Research Foundation and Svenska kulturfonden. The funding bodies had no input regarding the design, management, or reporting of the trial.

\section{Open Access}

This article is distributed under the terms of the Creative Commons Attribution-NonCommercial 4.0 International License (http://creativecommons.org/ licenses/by-nc/4.0/), which permits any noncommercial use, distribution, and reproduction in any medium, provided you give appropriate credit to the original author(s) and the source, provide a link to the Creative Commons license, and indicate if changes were made.

Received: 26 August 2018 Accepted: 3 November 2018 Published online: 14 November 2018

\section{References}

1. Laver S, Farrow C, Turner D, Nolan J (2004) Mode of death after admission to an intensive care unit following cardiac arrest. Intensive Care Med 30:2126-2128. https://doi.org/10.1007/s00134-004-2425-z

2. Lemiale V, Dumas F, Mongardon N et al (2013) Intensive care unit mortality after cardiac arrest: the relative contribution of shock and brain injury in a large cohort. Intensive Care Med 39:1972-1980. https://doi. org/10.1007/s00134-013-3043-4

3. Llitjos J-F, Mira J-P, Duranteau J, Cariou A (2016) Hyperoxia toxicity after cardiac arrest: what is the evidence? Ann Intensive Care 6:1-9. https://doi. org/10.1186/s13613-016-0126-8

4. Buunk G, van der Hoeven JG, Meinders AE (1999) Prognostic significance of the difference between mixed venous and jugular bulb oxygen saturation in comatose patients resuscitated from a cardiac arrest. Resuscitation 41:257-262

5. Lemiale V, Huet O, Vigué B et al (2008) Changes in cerebral blood flow and oxygen extraction during post-resuscitation syndrome. Resuscitation 76:17-24. https://doi.org/10.1016/j.resuscitation.2007.06.028

6. Battisti-Charbonney A, Fisher J, Duffin J (2011) The cerebrovascular response to carbon dioxide in humans. J Physiol (Lond) 589:3039-3048. https://doi.org/10.1113/jphysiol.2011.206052

7. Tolner EA, Hochman DW, Hassinen P et al (2010) Five percent $\mathrm{CO}_{2}$ is a potent, fast-acting inhalation anticonvulsant. Epilepsia 52:104-114. https ://doi.org/10.1111/j.1528-1167.2010.02731.x
8. Shoja MM, Tubbs RS, Shokouhi G et al (2008) The potential role of carbon dioxide in the neuroimmunoendocrine changes following cerebral ischemia. Life Sci 83:381-387. https://doi.org/10.1016/j.lfs.2008.07.007

9. McKenzie N, Williams TA, Tohira H et al (2017) A systematic review and meta-analysis of the association between arterial carbon dioxide tension and outcomes after cardiac arrest. Resuscitation 111:116-126. https://doi. org/10.1016/j.resuscitation.2016.09.019

10. Eastwood GM, Schneider AG, Suzuki S et al (2016) Targeted therapeutic mild hypercapnia after cardiac arrest: a phase II multi-centre randomised controlled trial (the CCC trial). Resuscitation 104:83-90. https://doi. org/10.1016/j.resuscitation.2016.03.023

11. Ganga HV, Kallur KR, Patel NB et al (2013) The impact of severe acidemia on neurologic outcome of cardiac arrest survivors undergoing therapeutic hypothermia. Resuscitation 84:1723-1727. https://doi.org/10.1016/j. resuscitation.2013.07.006

12. Tiruvoipati R, Pilcher D, Botha J et al (2018) Association of hypercapnia and hypercapnic acidosis with clinical outcomes in mechanically ventilated patients with cerebral injury. JAMA Neurol. https://doi.org/10.1001/ jamaneurol.2018.0123

13. Mekontso Dessap A, Charron C, Devaquet J et al (2009) Impact of acute hypercapnia and augmented positive end-expiratory pressure on right ventricle function in severe acute respiratory distress syndrome. Intensive Care Med 35:1850-1858. https://doi.org/10.1007/s00134-009-1569-2

14. Pilcher J, Weatherall M, Shirtcliffe P et al (2012) The effect of hyperoxia following cardiac arrest: a systematic review and meta-analysis of animal trials. Resuscitation. 83:417-422. https://doi.org/10.1016/j.resuscitat ion.2011.12.021

15. Kilgannon JH, Jones AE, Shapiro Nl et al (2010) Association between arterial hyperoxia following resuscitation from cardiac arrest and in-hospital mortality. JAMA 303:2165-2171. https://doi.org/10.1001/jama.2010.707

16. Kilgannon JH, Jones AE, Parrillo JE et al (2011) Relationship between supranormal oxygen tension and outcome after resuscitation from cardiac arrest. Circulation 123:2717-2722. https://doi.org/10.1161/CIRCU LATIONAHA. 110.001016

17. Bellomo R, Bailey M, Eastwood GM, Alistair N (2011) Arterial hyperoxia and in-hospital mortality after resuscitation from cardiac arrest. Crit Care 15:R90. https://doi.org/10.1186/cc10090

18. Janz DR, Hollenbeck RD, Pollock JS et al (2012) Hyperoxia is associated with increased mortality in patients treated with mild therapeutic hypothermia after sudden cardiac arrest. Crit Care Med 40:3135-3139. https:// doi.org/10.1097/CCM.0b013e3182656976

19. Roberts BW, Kilgannon JH, Hunter BR et al (2018) Association between early hyperoxia exposure after resuscitation from cardiac arrest and neurological disability. Circulation 137:2114-2124. https://doi.org/10.1161/ CIRCULATIONAHA. 117.032054

20. Elmer J, Scutella M, Pullalarevu R et al (2014) The association between hyperoxia and patient outcomes after cardiac arrest: analysis of a high-resolution database. Intensive Care Med 41:49-57. https://doi. org/10.1007/s00134-014-3555-6

21. Vaahersalo J, Bendel S, Reinikainen M et al (2014) Arterial blood gas tensions after resuscitation from out-of-hospital cardiac arrest: associations with long-term neurologic outcome. Crit Care Med 42:1463-1470. https ://doi.org/10.1097/CCM.0000000000000228

22. Nolan JP, Soar J, Cariou A et al (2015) European resuscitation council and European society of intensive Care medicine guidelines for postresuscitation care 2015: section 5 of the European resuscitation council guidelines for resuscitation 2015. Resuscitation 95:202-222. https://doi. org/10.1016/j.resuscitation.2015.07.018

23. Jakkula P, Reinikainen M, Hästbacka J et al (2017) Targeting low- or highnormal carbon dioxide, oxygen, and mean arterial pressure after cardiac arrest and resuscitation: study protocol for a randomized pilot trial. Trials 18:1-9. https://doi.org/10.1186/s13063-017-2257-0

24. Streitberger KJ, Leithner C, Wattenberg M et al (2017) Neuron-specific enolase predicts poor outcome after cardiac arrest and targeted temperature management. Crit Care Med 45:1145-1151. https://doi. org/10.1097/CCM.0000000000002335

25. Shinozaki K, Shigeto O, Sadahito T, Nakamura M (2009) S-100B and neuron-specific enolase as predictors of neurological outcome in patients after cardiac arrest and return of spontaneous circulation: a systematic review. Crit Care. https://doi.org/10.1186/cc7973 
26. Sandroni C, Cavallaro F, Callaway CW et al (2013) Predictors of poor neurological outcome in adult comatose survivors of cardiac arrest: a systematic review and meta-analysis. Part 1: Patients not treated with therapeutic hypothermia. Resuscitation 84:1310-1323. https://doi. org/10.1016/j.resuscitation.2013.05.013

27. Calderon LM, Guyette FX, Doshi AA et al (2014) Combining NSE and S100B with clinical examination findings to predict survival after resuscitation from cardiac arrest. Resuscitation 85:1025-1029. https://doi. org/10.1016/j.resuscitation.2014.04.020

28. Sandroni C, D'Arrigo S, Nolan JP (2018) Prognostication after cardiac arrest. Curr Opin Crit Care. https://doi.org/10.1186/s13054-018-2060-7

29. Stammet P, Collignon O, Hassager C et al (2015) Neuron-specific enolase as a predictor of death or poor neurological outcome after out-ofhospital cardiac arrest and targeted temperature management at $33^{\circ} \mathrm{C}$ and $36^{\circ} \mathrm{C}$. J Am Coll Cardiol 65:2104-2114. https://doi.org/10.1016/j. jacc.2015.03.538

30. Lång M, Skrifvars MB, Siironen J et al (2018) A pilot study of hyperoxemia on neurological injury, inflammation and oxidative stress. Acta Anaesthesiol Scand 62:801-810. https://doi.org/10.1111/aas.13093

31. Falkenbach $P$, Kämäräinen $A$, Mäkelä A et al (2009) Incidence of iatrogenic dyscarbia during mild therapeutic hypothermia after successful resuscitation from out-of-hospital cardiac arrest. Resuscitation 80:990-993. https:// doi.org/10.1016/j.resuscitation.2009.04.044

32. Kuisma M, Boyd J, Voipio V et al (2006) Comparison of 30 and the $100 \%$ inspired oxygen concentrations during early post-resuscitation period: a randomised controlled pilot study. Resuscitation 69:199-206. https://doi. org/10.1016/j.resuscitation.2005.08.010

33. Storm C, Leithner C, Krannich A et al (2014) Regional cerebral oxygen saturation after cardiac arrest in 60 patients: a prospective outcome study. Resuscitation 85:1037-1041. https://doi.org/10.1016/j.resuscitat ion.2014.04.021

34. Taccone FS, Crippa IA, Creteur J, Rasulo F (2018) Estimated cerebral perfusion pressure among post-cardiac arrest survivors. Intensive Care Med 44:966-967. https://doi.org/10.1007/s00134-018-5074-3

35. Witsch J, Frey H-P, Schmidt JM et al (2017) Electroencephalographic periodic discharges and frequency-dependent brain tissue hypoxia in acute brain injury. JAMA Neurol 74:301-309. https://doi.org/10.1001/jaman eurol.2016.5325

36. Laurent I, Monchi M, Chiche J-D et al (2002) Reversible myocardial dysfunction in survivors of out-of-hospital cardiac arrest. J Am Coll Cardiol 40:2110-2116

37. Stub D, Smith K, Bernard S et al (2015) Air versus oxygen in ST-segment elevation myocardial infarction. Circulation 131:1-41. https://doi. org/10.1161/CIRCULATIONAHA.114.014494

38. Hofmann R, James SK, Jernberg T et al (2017) Oxygen therapy in suspected acute myocardial infarction. N Engl J Med 377:1240-1249. https:// doi.org/10.1056/NEJMoa1706222 